\title{
HOUSEHOLD COPING STRATEGIES IN NATURAL COASTAL RISK AND DISASTER IN PAG-ASA, SAN JOSE, OCCIDENTAL MINDORO
}

\author{
Mary Yole Apple Declaro-Ruedas
}

College of Agriculture, Occidental Mindoro State College, San Jose, Occidental Mindoro, Philippines.

E-mail: tsinelas_yole@yahoo.com

Citation: Declaro-Ruedas, M.Y.A. 2018. Household Coping Strategies in Natural Coastal Risk and Disaster in Pag-Asa, San Jose, Occidental Mindoro. J. Asian Rur. Stud. 2(2): 124-131

\begin{abstract}
The study was conducted to determine the profile of the household heads; the level of household coping strategies in natural risk and disaster, and the relationship between profile and the household coping strategies.It used correlational method of research. Sixty-three household heads in barangay Pag-asa, San Jose, Occidental Mindoro served as the respondents of the study. Mean, frequency, and Pearson Moment Correlation were used in the study. Results revealed that majority of the respondents were middle aged, had reached Grade 7, medium size household, long length of residency with an average monthly income below the poverty threshold of the province. It was also found out that coastal household "moderately adopted" the different coping mechanisms in natural disasters and that household size and number of years spent in formal education has significant relationship with the coping mechanisms.
\end{abstract}

Keywords: Coping Strategies; Source of Information; Natural Disaster

\section{Introduction}

Even According to the World Risk Index, six out of the world's ten highest disaster risk countries are in Asia and the Pacific (Birkmann et al., 2011). Asian communities are thus extremely vulnerable to disasters, which are caused by natural hazards — such as earthquakes, tsunamis, cyclones, droughts, landslides, and flood.

Coasts and islands are highly exposed to a variety of climate hazards (Westmacott, 2002). Archipelago and small island states in Southeast Asia-where many poor communities live in coastal areas - are particularly vulnerable to the impacts of hydrometeorological hazards. In the first decade of the 21 st century, the death toll from disasters caused by natural hazards in Southeast Asia constituted nearly half of Asia and the Pacific as a whole (UNESCAP, 2012).

The inhabitants of coastal areas are more exposed to specific hazards such as coastal flooding, cyclones and tsunami, among which cyclone and induced surges are the most recurrent natural hazard (Wisner et al., 2004). The people of this area lose their lives and livelihoods disproportionately due to the tropical cyclones. However, they strive to return their normal life following any extreme climatic event, which is called resiliency. The term resilience is defined by the United Nations International Strategy for Disaster Reduction (UNISDR) as "the ability of a system, community or society 
exposed to hazards to resist, absorb, accommodate to and recover from the effects of a hazard in a timely and efficient manner, including through the preservation and restoration of its essential basic structures and functions" (UNISDR, 2009).

According to Oliver-smith (1998) cited in Rodriguez and Russell (2006), disasters are a combination of a "destructive agent" and a vulnerable group, resulting in societal disruption. Disaster cycle is a sequential phenomenon with pre-event situation followed by disaster and then by the post-event situation. On pre-event situation, it is the preparedness of society or its preparation steps for facing such extreme hazards; and on the post-event situation, it is the emergency phase and recovery after the phenomena play on the area. Resilience is on the pre-event situation, the risk will be on disaster, and damages and casualties are on the post-event situation. Post-event can be lessened or reduced by the use of pre-event situation properly (Pelling, 2013).

While the impacts of climate change have been more evident (IPCC, 2007), there is limited understanding on the extent of vulnerability and adaptive capacities of different communities such as those of the coastal areas.

Resilience is a dynamic interaction between perceived risk and a range of protective coping skills that provide an individual with the ability to adapt well in the face of adversity and thrive in everyday life (Miremadi, 2013). The interplay between perceived vulnerability and initiating the use of self-protective factors arises from an individual's view of the world and their role in it as they search for positive survival adaptations. Research suggests that one's degree of resilience may be modifiable, and changes affect individuals on a physiological, cellular, and perhaps even genetic level (Spangler, 2012).

Coping involves purposeful attempts to manage stress regardless of effectiveness (Compas, Malcarne, \& Fondacaro, 1988). According to Docena (2015), adaptive coping refers to the cognitive and behavioral efforts to manage internal and external demands that are taxing or exceeding the resources of the person." Both resilience and adaptive coping have been studied in the context of disasters. As a result, resilience may be described as the ability to cope positively.

Thus, this study provides household level analysis of the coping strategies the people follow during the occurrence of natural coastal disasters. Households are taken as the unit of analysis because the decision of choosing coping strategies is taken primarily at household level. Rashid et al. (2006) contend that the pattern of coping strategies that households adopt depends on specific characteristics of households and the nature of the shock that the households experience.

The study aims to determine the demographic profile of the household head ( $\mathrm{HH})$, household coping strategies in natural coastal risk and disaster, and the relationship between the profile of the household head and the level of household coping strategies in natural risk and disaster.

\section{Methodology}

This descriptive study was conducted in barangay Pag-asa, San Jose, Occidental Mindoro on January to June 2017. There were 63 household heads served as the respondents in this study. They were selected using simple random sampling. Informed consent was sought prior to data gathering. The participation in this study was voluntary 
and the aim of the study was explained to the informants and confirmed that the interviews and other collected information will be used only for the research purpose.

The study used survey form and direct observations for collecting primary data. Frequency distribution and percentage was used for the profile of the respondents. Mean analysis was used to determine the level of preparedness. Lastly, to determine the relationship between variables, the Pearson Moment correlation was used.

\section{Result and Discussion}

\subsection{Profile of the household heads in Pag-asa,San Jose, Occidental Mindoro}

The barangay Pag-asa in San Jose, Occidental Mindoro is predominantly coastal areas with a diverse economic activities. However, the majority of the working force are still engaged in fishing and fishing-related activities. According to the Municipal Agricultural Office of San Jose Occidental Mindoro, as of 2015 Barangay Pag-Asa has the second highest number of fishermen in town.

Table 1 shows the profile of the 63 household heads in Barangay Pag-asa, San Jose Occidental Mindoro. The household heads were in their middle age, with a mean age of 43.5 ranging from 22-64 years old. They have medium household size with an average of 6.78 members. They have resided in the coastal areas for almost 15.64 years. They are literate with an average years spent in formal education of 7.87 years. It indicates that majority of the fisherfolk had completed elementary level. This corroborates with the study of Dagos and Orfiano (2015), wherein majority of the fisher folk are elementary graduate.

The average monthly income, which stood at $\mathrm{PhP} 9,763.00$ falls below the poverty threshold of the province which is $\mathrm{PhP}$ 17,411.60 (PSA, 2012). The poverty incidence among households in MiMaRoPa is 22 percent in 2015. This means that 1 out of 5 families had an income lower than the poverty threshold or the minimum income to meet the basic food and non-food necessities.

Poverty is a static concept measured in terms of a minimum level of income and consumption, whereas vulnerability is a dynamic concept characterized by changes in socio-economic status and refers to an inability to cope with shocks and stresses (Vatsa, 2004). Poverty is an important aspect of vulnerability because of its direct association with access to resources (Adger, 1999). Poor people are more exposed to hazards, suffer greater relative loss of livelihood assets and have a much lower capacity to recover (Adger and Kelly, 1999).

Table 1. Profile of the household heads.

\begin{tabular}{lcc}
\hline \multicolumn{1}{c}{ Profile } & Mean & Range \\
\hline Age & 43.5 years old & $22-64$ years old \\
Household size & 6.78 members & $4-10$ members \\
Number of years spent in formal education & 7.87 years & $5-14$ years \\
Length of residency & 15.64 years & $8-52$ years \\
Monthly income & PhP 9,763.00 & PhP 5,000-23,000.00 \\
\hline
\end{tabular}




\subsection{Coastal hazards that mostly affect the community in Pag-asa, San Jose, Occidental Mindoro}

The Philippine archipelago is one of the most disaster-prone areas of the world, with a wide span of different hazards like tropical cyclones, accompanied by strong winds, intense rainfall and flooding, storm surges, flash floods, droughts caused by El Nino, earthquakes and volcanic eruptions. Due to the location of the Philippines, there is an increasing risk from the impacts of more frequent and extreme climate-related events. According to the World Meteorological Organization (ud), the Philippines has seen three times the global average in sea level rise since the year 1901(60 cm, against the global average of $19 \mathrm{~cm}$ ).

The coastal hazards "always" experienced by the residents in Pag-asa, San Jose, Occidental Mindoro are storm surge (mean=4.56), coastal flooding (mean=4.56), typhoons/storms (mean=4.58) and coastal erosion (mean=4.53).

Tropical cyclones accompanied by strong winds, intense rainfall and flooding represent the major hydrometeorological hazards in the Philippines. The climate of the country is strongly affected by rain-bearing (monsoon) winds, which blow from the southwest from May to October and from the northeast from November to February. From June to December, an average of twenty typhoons hit the country, out of which five to seven per year are expected to be destructive (Swiss NGO DRR Platform, 2014).

Most of the casualties and damage from cyclones are caused by storm surges and not by high wind speeds or rainfall as is usually believed. The northwestern part and some central areas also have a high risk to Tsunamis caused by seismic activities, but showing similar effects as storm surges. Floods are usually triggered by typhoons, tropical depression and continuing heavy rains. The annual monsoon season brings severe flooding to most areas of the country. For example in 2011, most of the disasters that claimed the lives of people and affected properties and livelihoods of the most vulnerable were of extensive nature, brought about by increased rainfall which caused massive flash flooding in areas that don't normally experience such conditions.

Table 2. Coastal hazards experienced by the respondents.

\begin{tabular}{|c|c|c|}
\hline Coastal Hazards & Mean & Interpretation \\
\hline Storm surge & 4.56 & Always \\
\hline Coastal Flooding & 4.56 & Always \\
\hline Typhoons/Storms & 4.58 & Always \\
\hline Tsunamis & 1.72 & Occasionally \\
\hline Monsoons & 4.26 & Frequently \\
\hline Coastal erosion & 4.53 & Always \\
\hline Grand Mean & 4.035 & Frequently \\
\hline
\end{tabular}

Legend: $0.50-1.50=$ never $; 1.51-2.50=$ Occasionally $; 2.51-3.50=$ Sometimes $; 3.51-4.50=$ Frequently; .51 $5.00=$ Always 


\subsection{Household coping strategies in natural coastal risk and disaster}

Coping response reveals an individual's perceptions and efforts to manage resources for mitigating the adverse consequences of hazards (Haque, 1997 \& Wisner et $a l ., 2004)$. It usually begins when the household is required to mobilize its assets to respond to a crisis; such as consumer savings, asset disbursement, borrowing from kin and patrons etc. (Adams et al., 1998). Coping strategies may be successful if a household is able to allocate resources to overcome a crisis without compromising the long term objective of livelihood security.

The household in Pag-asa, San Jose, Occidental Mindoro "moderately" employs the different coping strategies with a mean of 3.04. The "highly adopted" coping strategies were practice of other fisheries-related employment such as fish drying and fish vending (mean=4.24), engage in non-fishery labour like tricycle driving and construction work (mean $=4.25)$, reinforcement of houses (mean=4.46), migration to urban areas for livelihood (mean=3.66), reliance on traditional weather forecasting especially by fishermen (mean=4.26), and practice "bayanihan" in rebuilding houses, and communities (mean=4.32).

This is supported by Hussein and Nelson (1999) that "migration forms a central part of rural people's risk mitigation strategies". They further suggest that "migration forms a central component of livelihood diversification" and is generally considered an important livelihood strategy.

It is still common in coastal communities to practice "bayanihan," a voluntary collective action of people to assist those in need, such as moving a hut to another place and helping neighbors. During the actual hazard, bayanihan takes centre stage as people help each other (pagtutulungan), share one's burden (padadamayan) and empathize with one another (pakikiramay). Their faith and religious rituals help them endure losses, build inner resilience and give them hope that they will be able to recover with the help of God. Thus, praying to God is a "very highly" adopted coping strategy (mean=4.56).

In addition, old fisher folks also rely on natural phenomena to forecast weather by observing the stars and the sky. Some relate animal behaviour to the coming of the rain and storms. When they are sure of the coming storms, people use these indigenous knowledge systems to prepare for the disaster. They have developed an early warning system such as reinforcing their houses, and preserve food that will enable them to eat without cooking during a storm.

Getting of loans is a "moderately" adopted strategy (mean=3.46), while selling of assets is "slightly" adopted (mean=1.86). del Ninno et al. (2001) reveals the coping strategies of households includes borrowing, reducing expenditure and selling assets. While, Frankenberger (1992) classifies asset disposal as a coping strategy in several phases, with liquid assets, such as small livestock and jewelry disposed of first and productive assets later. When productive assets are disposed of, it becomes more difficult for a person or household to return to a pre-crisis state. An individual or household may finally attempt to migrate after having failed to cope with the crisis. 
Table 3. Household coping strategies employed.

\begin{tabular}{|c|c|c|}
\hline Coping Strategies & Mean & Interpretation \\
\hline \multicolumn{3}{|l|}{ Before } \\
\hline Longer time fishing in good weather. & 3.46 & Moderately adopted \\
\hline $\begin{array}{l}\text { Practice of other fisheries-related employment } \\
\text { (e.g. fish drying and fish vending). }\end{array}$ & 4.24 & Highly adopted \\
\hline $\begin{array}{l}\text { Engage in non-fishery labour (e.g. tricycle } \\
\text { driving and construction work such as painting } \\
\text { and carpentry). }\end{array}$ & 4.25 & Highly adopted \\
\hline Small business operation (e.g sari-sari store). & 1.12 & Not adopted \\
\hline $\begin{array}{l}\text { Diversification of food sources (e.g. drying fish } \\
\text { and gathering shellfish). }\end{array}$ & 1.72 & Slightly adopted \\
\hline Reinforcement of houses. & 4.46 & Highly adopted \\
\hline Sub mean & 3.21 & Moderately adopted \\
\hline \multicolumn{3}{|l|}{ During } \\
\hline Reliance on traditional weather forecasting. & 4.26 & Highly adopted \\
\hline Praying to God. & 4.56 & Very Highly adopted \\
\hline Increase food stocks. & 1.12 & Not adopted \\
\hline Prepare first aid kits. & 1.12 & Not adopted \\
\hline Sub mean & 2.77 & Moderately adopted \\
\hline \multicolumn{3}{|l|}{ After } \\
\hline Migration to urban areas for livelihood. & 3.66 & Highly adopted \\
\hline Build small dikes around the household. & 1.72 & Slightly adopted \\
\hline $\begin{array}{l}\text { Sale of assets (e.g. household appliance, land } \\
\text { and livestock). }\end{array}$ & 1.86 & Slightly adopted \\
\hline Getting of Loans & 3.46 & Moderately adopted \\
\hline $\begin{array}{l}\text { Practice "Bayanihan" in rebuilding houses, and } \\
\text { communities. }\end{array}$ & 4.32 & Highly adopted \\
\hline Change of settlement temporarily & 1.83 & Slightly adopted \\
\hline Receive rehabilitation relief. & 4.56 & Highly adopted \\
\hline Sub mean & 3.06 & Moderately adopted \\
\hline
\end{tabular}

Legend: $0.50-1.50=$ not adopted; $1.51-2.50=$ slightly adopted; $2.51-3.50=$ moderately adopted; $3.51-4.50=$ highly adopted;4.51-5.00 = very highly adopted

\subsection{Relationship between the profile of household and coping strategies in natural coastal risk and disaster}

The hypothesis was tested using Pearson Product Moment Correlation to determine the relationship between the profile of the household head and the level of household coping strategies in natural risk and disaster. The results of the findings revealed that the coping strategies of the respondents were influenced by household size and number of years spent in formal education at $5 \%$ level of significance.

Likewise, Sidame and Gurange (2009) revealed that there is a relationship between household size (sometimes approximated by the total number of children) and coping strategies. While, educational status of the household head and household women, occupation of the household's main earner, household income... were found to be independently and significantly associated with adaptation coping strategies (Farzana et al., 2017). 
Table 4. Relationship between the household head profile and their coping strategies.

\begin{tabular}{lccl}
\hline \multirow{2}{*}{$\begin{array}{c}\text { Socio-demographic } \\
\text { characteristics }\end{array}$} & \multicolumn{2}{c}{ Coping Strategies } & \multirow{2}{*}{ Interpretation } \\
\cline { 2 - 3 } \cline { 2 - 3 } & Computed $\boldsymbol{r}$ & Critical $\boldsymbol{r}$ & \\
\hline Age & 0.021 & 0.150 & Not Significant \\
Household size & 0.163 & 0.150 & Significant \\
Number of years spent in formal education & 0.175 & 0.150 & Significant \\
Length of residency & 0.024 & 0.150 & Not Significant \\
Monthly income & 0.018 & 0.150 & Not Significant \\
\hline
\end{tabular}

\section{Conclusion}

The household heads in Pag-asa, San Jose, Occidental Mindoro were middle aged, had reached formal education, medium size household, long length of residency with below average monthly income. The coastal households "moderately adopted" the different coping mechanisms in natural disasters. Household size and number of years spent in formal education has significant relationship with the coping mechanisms employed.

Based on the findings of the study, there is a need to strengthen existing linkages and invite other organizations with similar undertakings to improve the delivery of services before, during, and after disaster. Education, Information and Communication materials using vernacular language on disaster risk management can be develop to increase the community's awareness and preparedness.

\section{References}

Adger, N. 1999. Social Vulnerability to climate Change and Extremes in costal Vietnam. World Development, Vol. 27, No. 2

Birkmann, J., D. Krause, N.J. Setiadi, D.S. Suarez, T. Welle, J. Wolfertz, R. Dickerhof, P. Mucke, and K. Radtke. 2011. World Risk Report 2011. Berlin: Bündnis Entwicklung Hilft (Alliance Development Works).

Compas, B. E., Malcarne, V. L., \& Fondacaro, K. M. 1988. Coping with stressful events in older children and young adolescents. Journal of Consulting and Clinical Psychology, 56(3), 405.

Docena, P. 2015. Adaptive coping, resilience, and absence of anxiety among displaced disaster survivors. Retrieved July 17, 2017, from www.pap.org.ph/includes/view/default

Ellis, F. 1998. Livelihood Strategies and Rural Livelihood Diversification. Journal of Development Studies, Vol. 35, Issue. 1

Farzana, F.et al. .2017.. Coping strategies related to food insecurity at the household level in Bangladesh. Retrieved March 12, 2017, from https://doi.org/10.1371/journal.

Frankenberger, T. 1992. Indicators and data collection methods for assessing household food security, in Maxwell, S. \& Frankenberger, T. (eds.). Household food security: concepts, indicators, and measurements: a technical review. New York and Rome: UNICEF and IFAD. 
Hussein, K. and Nelson, J. 1999 Sustainable Livelihoods and Livelihood Diversification. IDS Working Paper 69. Brighton: Institute of Development Studies.

Rashid, D., Lanngworthy, M. and Aradhyula, S. 2006. Livelihood shocks and coping strategies: An Empirical Study of Bangladesh Households. Retrieved March 24, 2017, from ageconsearch.umn.edu/bitstream/21231/1/sp06ra10.pdf

Rodriguez, H. and Russell, C.N. 2006.Understanding Disasters: Vulnerability, Sustainable Development, and Resiliency, in Judith Blau and Keri Iyall-Smith (Eds.). Public Sociologies Reader. New York: Rowman \& Littlefield.

Rodriguez, H., Quarantelli, E. L. \& Dynes, R. 2006. Handbook of Disaster Research. New York: Springer.

Twigg, J. 2001. Sustainable Livelihoods and Vulnerability to Disasters. BenfieldGreig Hazard Research Centre for the Disaster Mitigation Institute.

UNESCAP (United Nations Economic and Social Commission for Asia and the Pacific). 2012. Statistical Yearbook for Asia and the Pacific 2012. Retrieved March 24, 2017, from http://www.unescap.org/stat/data/syb2012/index.asp.

UNESCO (United Nations Educational, Scientific and Cultural Organization). 2009. Climate Change and Arctic Sustainable Development: Scientific, social, cultural and educational challenges. Paris: UNESCO.

UNESCO. Undated. What is Local and Indigenous Knowledge? Retrieved March 24, 2017, from http://www.unesco.org/ new/en/natural-sciences/priorityareas/links/relatedinformation/what-is-local-and-indigenous-knowledge/.

Vatsa, S. 2004. Risk, Vulnerability and Asset-based Approach to Disaster Risk Management. International Journal of Sociology and Social Policy. Vol. 24 $(10 / 11)$.

Westmacott, S. 2002. 'Where should the Focus be in Tropical Integrated Coastal Management', Coastal Management, Vol. 30

Wisner, B., Blakie, P., Cannon, T., Davies, I. 2004. At Risk. London and New York: Routledge. 